\title{
PAIS FUMANTES: O QUE PENSAM SEUS FILHOS?
}

\section{SMOKING PARENTS: WHAT DO THEIR CHILDREN THINK?}

Lefèvre AMC, Pereira IMB, Oliveira NGS, Lefèvre F, Stewien GTM, Mirra AP, Simioni APC. Pais fumantes: o que pensam seus filhos? Rev Bras Crescimento Desenvolv Hum. 2006;(2):53-68.

Resumo: A presente pesquisa ${ }^{+}$foi realizada com a finalidade de alcançar uma melhor comprensão da dinâmica familiar em lares de pais fumantes. O foco está no relacionamento entre pais fumantes e seus filhos e o ponto central é o fato do tabagismo passivo ser a terceira maior causa de morte evitável no mundo. Fizeram parte do estudo 41 crianças e 22 adultos. A opção metodológica é de corte quali-quantitativo, sendo utilizada a técnica do Discurso do Sujeito Coletivo-DSC. Na pesquisa com as crianças, ressaltou-se que pais fumantes poderiam levar os filhos a fumar; entretanto a maioria das crianças entrevistadas declarou que não pretende fumar e a razão mais freqüentemente apontada foi o medo das doenças e mesmo da morte. Parte considerável das crianças declara que os pais fumam em sua presença e se revelaram incomodadas com isso. Os pais dizem não fumar na presença dos filhos, percebendo-se uma consciência dos males do cigarro para o fumante passivo. Por se tratar de um estudo inicial, com uma amostra pequena, as conclusões não podem ser generalizadas para todo tipo de pré-adolescentes desta faixa etária, nem mesmo para a população de escolares desta mesma faixa etária. Ressalte-se, no entanto, que de um ponto de vista qualitativo, os resultados sugerem uma ampla variedade de temas e sub temas a serem explorados em pesquisas posteriores.

Palavras-chave: Tabagismo. Fumante passivo. Discurso do sujeito coletivo.

\section{INTRODUÇÃO}

Segundo Rosemberg ${ }^{1}$, o tabagismo acontece entre os homens desde tempos remotos.
Através dos anos ganhou cada vez mais adeptos entre diferentes extratos da população, conquistando sempre mais espaços, até se tornar indispensável no cotidiano de seus praticantes.

\footnotetext{
* Doutora em Saúde Pública pela USP, pesquisadora do Instituto de Pesquisa do Discurso do Sujeito Coletivo. Email ana@ipdsc.com.br

** Profa Doutora da Faculdade de Saúde Pública da USP

*** Doutora em Psicologia pela USP

\# $\quad$ Prof. titular da Faculdade de Saúde Pública da USP

\# Profa Doutora da Faculdade de Saúde Pública da USP

§ Coordenador do Registro de Câncer da Faculdade de Saúde Pública da USP

$\S \S \quad$ Profa Doutora da EACH - USP

+ O O presente texto foi extraído da pesquisa “Criança: um fumante passivo sem opção” desenvolvida na Faculdade de Saúde Pública da USP, sob a coordenação dos Professores Isabel Maria Teixeira Bicudo Pereira, Glacilda Telles de Menezes Stewien, Antonio Pedro Mirra, sob a assessoria dos Professores Fernando Lefèvre e Ana Maria Cavalcanti Lefèvre com a participação das pesquisadoras Ivany Yara de Medeiros, Neusa Guaraciaba dos Santos e Ana Paula Cavalcanti Simioni, com as coordenação de campo de Maísa Rose Domenico Elmor
} 
Por seu alto potencial de morbidade e mortalidade é considerado como grave problema de saúde pública, caracterizado como pandemia que, nos paises não participantes do primeiro mundo, está em pleno florescimento.

No mundo há 1 bilhão e 260 milhões de fumantes, com predominância nos paises em desenvolvimento (860 milhões) e 400 milhões nos paises desenvolvidos. No Brasil estima-se em 30,6 milhões de fumantes (acima de 15 anos), dos quais 40,3\% ocorrem nos homens e 26,2\% nas mulheres.

O consumo de cigarros é de 7 trilhões e 30 bilhões de cigarros/ano, sendo fumados 20 bilhões diariamente. No Brasil consome-se 149 bilhões de cigarros/ano. Inala-se 75 mil toneladas de nicotina anualmente, distribuindo-se em 200 toneladas diárias.

O tabaco, no mundo, mata 1 em cada 10 adultos e projeta-se para o ano de 2030 a proporção de 1 em cada 6 . É responsável por 2,6\% da mortalidade total, devendo triplicar em 2020, atingindo 8,9\%. No ano 2002 a mortalidade total devida ao tabagismo foi de 5 milhões, sendo 3,5 milhões nos paises em desenvolvimento e até 1,5 milhões naqueles desenvolvidos.

Caso o atual padrão de consumo de tabaco continuar presente, em 2030 a mortalidade atingirá 10 milhões, sendo 3 milhões nos paises ricos e 7 milhões nos mais pobres. No Brasil, dados da OPS apontam que 200 mil morrem por ano por doenças tabaco relacionadas.

Segundo Mahler $^{2}$, o consumo de tabaco vem diminuindo $1 \%$ ao ano em paises industrializados e, simultaneamente, vem aumentando nos paises em desenvolvimento; entretanto, os estudiosos do assunto afirmam que, atualmente, em ambos os casos o tabagismo está crescendo de forma preocupante entre crianças e adolescentes.

Nas grandes cidades, o fumo polui mais séria e nocivamente o ambiente do que as indústrias e os veículos automotores, segundo
Ferreira et al $^{3}$. Isso remete ao fato de que ele afeta não só aqueles que praticam o tabagismo, mas também os que estão ao seu lado e que constitui o que se denomina "fumante passivo".

Para Ferreira et $\mathrm{al}^{3}$, "o fumante passivo, aquele que fuma involuntariamente por estar no mesmo ambiente com fumantes ativos, pode conter no sangue, urina e saliva, quantidade de nicotina equivalente à encontrada em fumantes de 1 a 10 cigarros/ dia, dependendo do numero de horas de exposição e da poluição ambiental”.

Os fumantes inalam $25 \%$ da fumaça dos cigarros; o restante fica no ambiente, sendo inalada pelos não fumantes, com o agravante de que estes não contam com a pretendida barreira representada pelo filtro, presente em vários cigarros.

Com base nas evidências cientificas dos efeitos que fumantes passivos sofrem em suas condições respiratórias, a U. S. Environmental Protection Agency conclui que a exposição à fumaça do tabaco constitui sério impacto sobre a saúde pública, acarretando câncer de pulmão e de outras localizações nos adultos e aumentando o risco de uma série de outros agravos respiratórios especialmente em crianças, segundo Kumar e Melville ${ }^{4}$.

O tabagismo passivo é considerado a terceira maior causa de morte evitável no mundo, seguindo-se ao tabagismo ativo e ao consumo excessivo de álcool. Estima-se no mundo 2 bilhões de fumantes passivos, dos quais $70 \mathrm{mi}-$ lhões são crianças até 15 anos. No Brasil esse grupo etário é estimado em 15 milhões.

Rosemberg ${ }^{5}$, referindo-se aos fumantes passivos, afirma que nas crianças, há incremento de casos de bronquite, pneumonia, asma, infecções do ouvido médio, aumento dos casos de infecções respiratórias em bebês e crianças menores de 2 anos, morte súbita, e maior risco de câncer de pulmão na idade adulta; quanto maior o numero de fumantes no domicilio, maior é a incidência dessas infecções respiratórias. 
Kursz et al. ${ }^{6}$ acrescenta a esse quadro, o aumento de risco dessas crianças desenvolverem, mais tarde, doenças pulmonares crônicas de caráter obstrutivo.

\section{JUSTIFICATIVA}

Atendendo às pressões de profissionais da saúde e grupos organizados da sociedade civil, a legislação mundial tem avançado, embora vagarosamente, no sentido de proteger a saúde dos não fumantes, limitando cada vez mais os espaços coletivos onde o tabagismo é permitido.

Contudo, todo esse arsenal de conhecimentos científicos, assim como a legislação existente, esbarram em obstáculos de difícil transposição: o comportamento e a vontade dos indivíduos que fumam. Freqüentemente, o fumante conhece os malefícios advindos do tabagismo sobre sua própria saúde e a dos que o cercam, mas mesmo assim, continua fumando. Ele dispõe da informação, mas esta não é o suficiente para mudar o seu comportamento. Todas as leis existentes não conseguem impedi-lo de fumar, principalmente, dentro de sua própria casa, na convivência com sua família.

Os fumantes constituem o exemplo clássico utilizado para ilustrar o modelo $\mathrm{CAP}^{++}$, segundo Candeias e Marcondes ${ }^{7}$ e Green e Kreuter ${ }^{8}$. Invariavelmente, eles sabem de todos os prejuízos inerentes ao vicio de fumar não só para si próprios, como para os que vivem ao seu lado. Com freqüência tem a intenção e a predisposição para abandonar esse vício, mas quando se vêem frente ao momento de concretizar essa intenção, outros fatores surgem, travestidos da maior importância e urgência, impedindo-os de abandonar esse comportamento, de acordo com Bott et al ${ }^{9}$.

Entretanto, essa concepção se torna complexa quando a relação entre fumante e fuman- te passivo se concretiza nas figuras de pais e filhos. Como explicar que pais, conscientes e voluntariamente possam prejudicar a qualidade de vida de seus filhos não só no presente, como também no futuro e, não só em termos de saúde, mas no que se refere a sua formação como cidadãos? Enquanto fumantes, que tipo de imagem acreditam eles estar passando para os filhos? Será que em algum momento param para ouvir o que os filhos pensam a respeito?

O presente estudo foi realizado com o propósito de equacionar essas hipóteses e de entender como funciona a dinâmica familiar envolvida nessa problemática. Pretendeu igualmente compreender a percepção que os pais têm enquanto atores principais do processo de deterioração da saúde de seus filhos e, também como as crianças se percebem enquanto fumantes passivos e como se relacionam com o universo familiar, onde o tabaco está presente cotidianamente.

\section{OBJETIVOS}

- Identificar, da perspectiva das crianças, o funcionamento da dinâmica familiar envolvida quando os pais são fumantes;

- Compreender a percepção que os pais têm enquanto atores principais no processo de deterioração da saúde de seus filhos enquanto fumantes passivos.

\section{MÉTODO}

A opção metodológica da presente pesquisa é de corte qualitativo. Esta opção prende-se ao fato de que o método qualitativo é capaz de "incorporar a questão do significado e da intencionalidade como inerentes aos atos, às relações e às estruturas sociais, sendo estas

\footnotetext{
$\overline{{ }^{++}}$A sigla quer dizer: C- conhecimentos; A- atitudes; P- práticas
} 
últimas tomadas tanto no seu advento quanto na sua transformação, como construções humanas significativas” Minayo ${ }^{10},{ }^{11}$.

Segundo Simioni et al ${ }^{12}$ (1996), "o significado e a intencionalidade ocupam posição central na pesquisa qualitativa uma vez que ela permite o resgate do significado através da análise dos discursos dos atores enquanto sujeitos da pesquisa e sujeitos sociais".

Decidiu-se para a presente pesquisa utilizar a metodologia do Discurso do Sujeito Coletivo-DSC, de Lefèvre e Lefèvre ${ }^{13}$, que representa um recurso metodológico destinado a tornar mais claras e expressivas as Representações Sociais, permitindo que um determinado grupo social possa ser visto como autor e emissor de discursos compartilhados entre os membros do grupo.

A técnica para a construção do Discurso do Sujeito Coletivo implica em selecionar, de cada resposta individual a uma questão, as Expressões Chave-ECH, que são trechos mais significativos destas respostas. A essas Expressões Chave correspondem Idéias Centrais-ICs, que são a síntese do conteúdo discursivo manifestado nas Expressões Chave. Com o material das Expressões Chave das Idéias Centrais semelhantes constroem-se discursos-síntese ou DSCs, na primeira pessoa do singular, com um número variado de participantes, onde o pensamento de um grupo ou coletividade aparece como se fosse um discurso individual. Uma vez "qualificada" a variável pelo DSC, ela passa a poder ser quantificada utilizando-se os recursos habituais de quantificação como gráficos, tabelas, etc.

Enquanto variável quantificável, cada DSC possui dois atributos que serão definidos a seguir: intensidade e amplitude. Intensidade refere-se ao número ou percentual de indivíduos que contribuíram, com suas ECHs relativas a ICs semelhantes ou complementares, para a confecção dos DSCs; ela permite saber, portanto, quais os DSCs dominantes, isto é, aqueles mais freqüentes; já amplitude refere-se à medida da presença do DSC considerando o campo ou universo pesquisado.

\section{Instrumentos}

Foram feitos dois questionários, um para crianças e outro para adultos. O pré-teste foi aplicado na própria Faculdade de Saúde Pública, em três funcionárias fumantes e seus respectivos filhos que freqüentavam a "sala de período complementar”, mas que na escola regular cursavam a $5^{\mathrm{a}}$ série do primeiro grau.

O questionário dos pais foi submetido ao pré-teste, não havendo necessidade de modificações. Com relação ao pré-teste das crianças percebeu-se que seria adequado anexar à parte verbal, algum tipo de estímulo visual que as motivasse falar. A equipe optou por uma figura apresentada no começo da entrevista, solicitando que a criança discorresse sobre ela. Foi acrescentado também, um cartaz, referente a segunda questão, objetivando garantir a compreensão da criança sobre a pergunta formulada.

\section{Roteiro de questões para entrevista das crianças}

1. Alguns meninos começam a fumar na sua idade. Por que você acha que isso aontece?

2.Agora eu vou falar 3 frases, você vai ouvir as três e depois escolher uma delas. Preste atenção.

Primeira: Eu não gostaria de fumar. vá fumar

Segunda: Não sei mas pode ser que eu

Terceira: Eu gostaria de fumar

(Depois da escolha dizer: "Então você escolheu a..., não é? Por que?)

3. O seu pai ou sua mãe costuma a fumar no lugar onde você está?

Caso sim: como é isso para você?

Caso não: como é para você seus pais 
fumarem?

4. Você quer perguntar alguma coisa?

\section{Roteiro de questões para entrevista dos pais}

1. O sr(a) costuma fumar no lugar onde seu filho está?

Caso sim: como é isso para você?

Caso não: passe para a questão seguinte

2. Você acha que o fato de você fumar causa algum problema para o seu filho, ou não? Por que?

3.Você acha que seu filho vai fumar?

Caso sim: como é isso para você?

Caso não: Por que?

4. Você quer perguntar alguma coisa?

Passou-se, a seguir, à aplicação da pesquisa, realizada em duas escolas, uma de ensino público e outra particular, ambas localizadas no Município de São Paulo. Foi considerado o universo total das crianças que freqüentavam a 5 a série, filhos de fumante (o pai, a mãe ou ambos) e seus respectivos pais. Fizeram parte do estudo 41 crianças e 22 adultos.

Como número de alunos da escola pública era muito superior ao da escola particular, resultou em um número superior de entrevistas na escola pública. Chegou-se a um universo de 41 crianças, as quais os pais consentiram que participassem do estudo. Destas, 6 pertenciam a escola particular e 35 a escola da rede pública de ensino

O coordenador de campo contatou os indivíduos a serem entrevistados. Os pais dos alunos foram esclarecidos sobre o objetivo da pesquisa e assinaram um termo de consentimento. As entrevistas foram realizadas nas próprias escolas, em sala destinada para este fim, no período de maio a agosto de 2003. Foram aplicadas por três entrevistadoras e gravadas em fitas magnéticas. Posteriormente foi feita a trans- crição e analisada por meio do software "qualiquantisoft” e do programa SPSSWIN.

\section{RESULTADOS}

\section{Perfil das crianças entrevistadas}

Foram entrevistadas crianças, com idade variando entre 10 e 15 anos (média de 11,12 anos), sendo 35 (85,4\%) alunos de escola pública e 06 (14,6\%) de escola particular. Do total de crianças entrevistadas, 20 (48,8\%) eram do sexo masculino e 21 (51,2\%) do sexo feminino. Entre os alunos entrevistados o percentual de pais fumantes foi de 48,8\% (20) quando apenas o pai era fumante, 24,4\% (10) apenas quando as mães eram fumantes e, por fim, 26,8\% (11) quando ambos eram fumantes.

\section{Crianças $^{+++}$}

\section{Questão 2}

Agora eu vou falar 3 frases e você vai escolher uma delas: eu não gostaria de fumar; não sei mas pode ser que eu vá fumar; eu gostaria de fumar.

As respostas a esta questão estão sintetizadas no quadro 1.

Quadro I- Síntese das idéias centrais das respostas das crianças à questão 2

\begin{tabular}{|c|c|c|}
\hline IDÉ IA CENTRAL & $\mathrm{N}^{0}$ & $\%$ \\
\hline $\begin{array}{l}\text { A - } 1^{\text {a }} \text { opção- Porque não gosta do } \\
\text { cheiro e nem da fumaça }\end{array}$ & 7 & 12.50 \\
\hline $\begin{array}{l}\text { B- } 1^{\text {a }} \text { opção- Porque é prejudicial à } \\
\text { saúde, pode dar câncer e levar até } \\
\text { à morte. }\end{array}$ & 33 & 59.01 \\
\hline C- $1^{\mathrm{a}}$ opção-Porque não quer. & 2 & 3.56 \\
\hline $\begin{array}{l}\text { D - } 1^{\text {a }} \text { opção- Por orientação dos } \\
\text { pais e outros adultos }\end{array}$ & 3 & 5.36 \\
\hline E- $1^{\text {a }}$ opção-Porque é uma droga. & 4 & 7.13 \\
\hline $\begin{array}{l}\text { F- } 1^{\text {a }} \text { opção-Porque prejudica os } \\
\text { outros }\end{array}$ & 3 & 5.36 \\
\hline G- $1^{\mathrm{a}}$ opção-Porque acha feio & 1 & 1.72 \\
\hline $\begin{array}{l}\mathrm{H}-2^{\mathrm{a}} \text { opção-Porque não sabe o } \\
\text { futuro. }\end{array}$ & 3 & 5.36 \\
\hline T O T A L & 56 & 100 \\
\hline
\end{tabular}

${ }^{++}$Nesse artigo serão apresentados apenas os resultados referentes às questões 2 e 3,tendo em vista a exigüidade do espaço disponível,considerando que na metodologia do DSC os resultados se desdobram em longos textos a serem apresentados. 


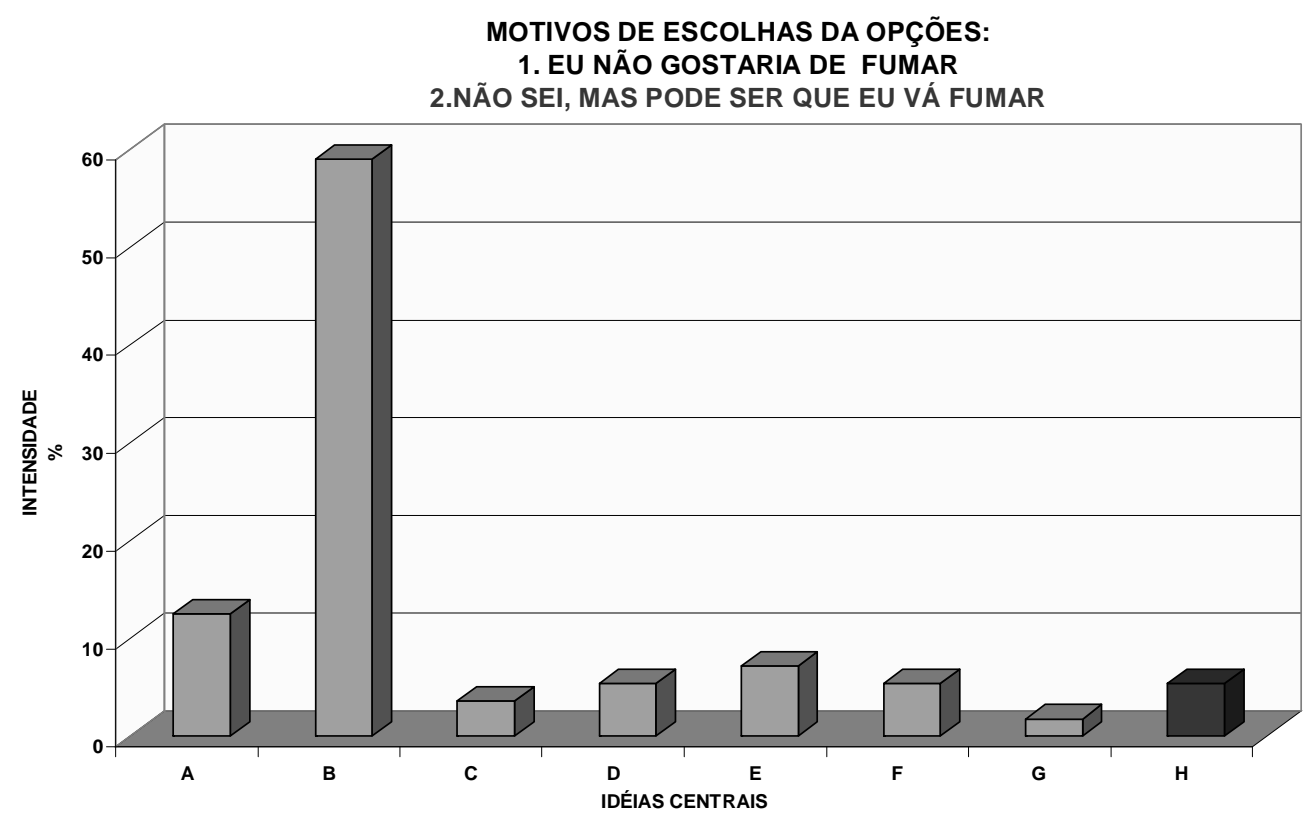

Em função da exiguidade de espaço serão apresentados apenas alguns DSCs considerados relevantes

DSC A - Porque não gosta do cheiro e nem da fumaça

Eu escolho a primeira, "Eu não gostaria de fumar". Ah, porque eu não gosto muito do cheiro de cigarro. ... eu me sinto mal de saber que eu estou perto de um cigarro, por causa da fumaça, tenho alergia à fumaça; eu não suporto nem o cheiro de cigarro, porque é cheiro muito ruim. Acho que, de vez em quando, em casa, a minha mãe fuma; eu sinto o cheiro, isso me incomoda o nariz. É ruim. ... Uma vez peguei o cigarro da boca dela e joguei no chão; ela me deixou de castigo, depois eu saí logo. Até a gente já falou, quando você fuma você não sente a fumaça. Você não sente. ... O meu pai fuma perto de mim, eu falo: "apaga isso; eu não gosto". Aí ele fala: "Então sai daqui. Não sei, mas eu não gosto mesmo de cigarro. Meu pai estava até parando de fumar. Aí começou a fumar por causa que fica nervoso, essas coisas. Aí fuma.
DSC B- $1^{\mathrm{a}}$ opção- Porque é prejudicial à saúde, pode dar câncer e levar até à morte.

"Eu não gostaria de fumar" Porque fumar não é uma coisa boa, é muito ruim, prejudica muito a saúde da pessoa. Eu acho muito errado as pessoas fumando; acho que estraga a pessoa, estraga o corpo da pessoa, não serve para nada - só para estragar sua vida... E mesmo porque cigarro tem nicotina e faz mal para o pulmão, quando a gente fuma muito, a gente fica com gripe e, além disso, eu tenho bronquite, faz mal. Não sei nem o porquê o cigarro veio a existir, porque cigarro só faz mal. Se fizesse bem, a gente poderia até usar... mas como não faz nenhum bem, não tenho curiosidade nem nada; eu nunca quero fumar na minha vida porque você estraga a sua vida, você não conserta a sua vida depois. Além disso, os dentes ficam amarelos do fumo, fica assim no pulmão, no coração; por causa que o cigarro, quando a gente usa, a fumaça dele, uma parte sai, a outra entra e fica no pulmão, apodrece o pulmão. A pessoa morre.

A pessoa pode, também, ter a vida mais curta. Tipo, você poderia morrer com seten- 
ta anos, você vive vinte anos menos... Tipo, morre com cinqüenta anos. É ruim fumar. $O$ cigarro pode prejudicar o pulmão, o fígado, dar mau hálito na boca, sujar e estragar os dentes, causar parada cardíaca, dependência sexual, muitos problemas... até morrer ou ficar muito doente. Pode poluir o pulmão, um negócio mais ou menos assim, poluir o pulmão; deixar seu pulmão uma porcaria cheio de bactérias, sujeira... e assim vai prejudicando a vida mais... Pode também ter um câncer. Quando você tem um câncer, eles vão tirando as suas partes aos poucos, seus órgãos. Aí os seus órgãos vão ser cremados, você morre em alguns meses ou até anos. Só que, em alguns casos, quando a pessoa já está fumando faz um monte de tempo, morre certíssimo. Esse é o caso da minha mãe. Ela fuma direto, e quando não tem cigarro, ela compra, gasta o dinheiro da passagem e compra.

Pelo que eu saiba também, as pessoas que fumam perdem a inteligência, uma parte mais útil, e perdem a consciência do que é certo e do que é errado. Se eu fumar até, assim, três maços, vários maços, eu posso me prejudicar no mesmo momento. O meu pai já foi parar no hospital por causa do fumo mesmo, e eu não gostaria de fazer o que ele fez. Então eu acho que não sei porquê as pessoas fumam.

Agrande maioria das crianças (categoria B 59,01\%) declarou que não pretende fumar. Arazão mais freqüentemente apontada, de forma espontânea, foi aquela ligada ao medo das doenças e mesmo da morte como ilustra a seguinte fala: ... Só que, em alguns casos, quando a pessoa já está fumando faz um monte de tempo, morre certíssimo.
Esse é o caso da minha mãe. Percebe-se que as crianças parecem estar fortemente influenciadas por campanhas realizadas na escola e na mídia, inclusive fantasiando alguns dos efeitos do fumo e até confundindo o cigarro com outras drogas como pode exemplificar este trecho do discurso: ....as pessoas que fumam perdem a inteligência, uma parte mais útil, $e$ perdem a consciência do que é certo e do que é errado...

\section{Questão 3}

O seu pai ou sua mãe costumam fumar no lugar onde você está?

As respostas a esta questão estão sintetizadas no quadro II.

Quadro II- Síntese das idéias centrais das respostas das crianças à questão 3

\begin{tabular}{|c|c|c|}
\hline IDÉIA CENTRAL & $\mathrm{N}^{0}$ & $\%$ \\
\hline $\begin{array}{l}\text { A- Sim, o pai e ou /mãe fumam no } \\
\text { local onde a criança se encontra. }\end{array}$ & 18 & 43.90 \\
\hline B- Sim, mas fuma escondido.. & 1 & 2.44 \\
\hline $\begin{array}{l}\text { C- Não, o pai e/ ou mãe não } \\
\text { fumam no local onde a criança } \\
\text { está. }\end{array}$ & 7 & 17.07 \\
\hline $\begin{array}{l}\text { D- Não, o pai e/ ou a mãe não } \\
\text { fumam na presença da criança, } \\
\text { mas esta cita o local onde fumam. }\end{array}$ & 10 & 24.39 \\
\hline $\begin{array}{l}\text { E- De vez em quando o pai e/ ou a } \\
\text { mãe fumam na presença da } \\
\text { criança. }\end{array}$ & 5 & 12.20 \\
\hline TOTAL & 41 & 100 \\
\hline
\end{tabular}

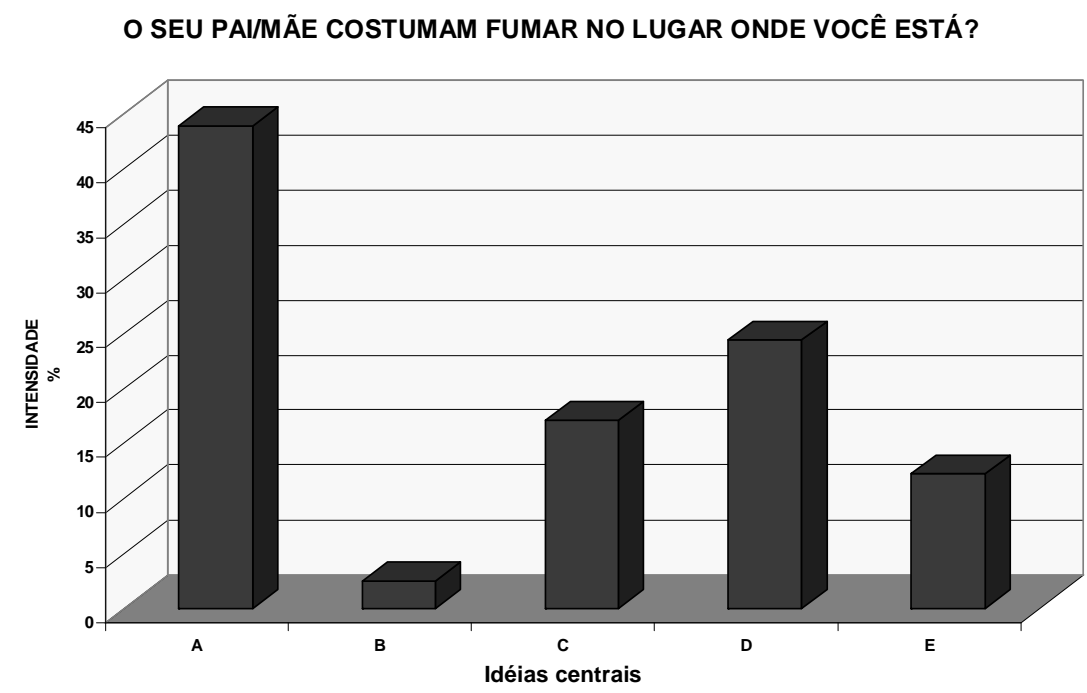


DSC A - Sim, o pai e ou/mãe fumam no local onde a criança se encontra.

Sim, eles fumam em qualquer lugar, só não fumam em lugar proibido $e$, às vezes, quando eu estou na casa da minha avó, eles não fumam perto de mim.

Meu pai não convive muito comigo, porque é separado da minha mãe. Mas meu padrasto também fuma. Ele fuma perto de mim, então eu deixo, num falo nada. Ele deve fumar longe, para não fazer mal, para mim mesmo também não fumar do cigarro dele, que é muito ruim. Também não gosto de ficar perto do meu pai, quando ele está fumando. Aí eu saio de perto, eu vou para outro local.

Normalmente, quando eu estou na $T V$, na sala, eles sentam lá para conversar, e acabam, assim, acendendo um cigarro. Se eu estou aqui no sofá, eu peço para ele fumar para lá, para a fumaça não ir bem na minha cara. Aí eu fico no sofá pequeno, ele fica lá fumando. Mas eu chego, abro a janela, ligo o ventilador, tudo, para sair a fumaça que o cheiro é desagradável, certo? Fica me dando uma fumaça! Eu não fico perto deles, fico longe, porque eu não gosto da fumaça e começo a tossir. Então eu vou para outro lugar, no computador ou no meu quarto, para ficar longe. Ele me chama, quando eu chego lá, ele pega outro cigarro e fuma de novo...Aí eu saio de novo, volto lá para o quarto. Quando ele me chama, eu não vou.

Meu pai fuma na cozinha, em tudo quanto é lugar. De vez em quando eu estou lá almoçando, eles chegam, às vezes sentam, e começam a fumar. Daí me atrapalha. Eu perco o apetite e fico enjoado. A fumaça vai entrar em mim, pode me dar ( vontade de) querer também fumar. É isso que eu acho, né? Que me dá influência.... Teve uma vez que eu fiquei gripada, e eu já tenho problemas de respiração - não é?
-, e minha mãe começou a fumar perto de mim. Aí eu reclamei com ela: "Mãe, pára de fumar perto de mim, porque você está fazendo eu também fumar junto com você." Aí agora ela começou a maneirar um pouco....

Meu pai fuma. Ele fuma mais quando está bebendo, quando está em festa. Eu falo para ele não fumar perto de mim, ele: "Ah, o quê que tem? Você não está fumando. "Então meu pai não liga muito se eu estou perto ou não.A minha mãe comprou aqueles negócio para você conseguir parar de fumar, até agora não conseguiu. Quando ela chega do trabalho ela acende o cigarro. Assim, ela está lá, daí eu estou sentada aqui. Ela senta e eu saio, estendeu? Ela estragou a vida dela, não quero estragar a minha.

DSC D- Não, o pai e/ ou a mãe não fumam na presença da criança, mas esta cita o local onde fumam.

Não. Eles fumam assim, a minha mãe, ela só fuma à noite, quando ela vai dormir. Aí, quando ela vai dormir, às vezes, eu já estou dormindo. Ela só fuma no quarto dela, que é privacidade dela. No meu quarto ela não fuma, no quarto da minha irmã ela não fuma. Só se quando a gente chegar, ela já estava fumando.

Ela também costuma fumar num lugar específico, lá fora, na sacada e na lavanderia... Se eu estou lá fora, aí no quintal, ela não fuma. Ela fuma num lugar específico. Aí o meu pai também. Ele trabalha, assim, e só chega à noite. Ele fuma no trabaIho, quando não tem ninguém para atender, que ele é farmacêutico. Ou quando ele não tem nada para fazer, ele sai para fora, vai dar uma volta na rua, e acaba fumando um ou dois cigarros.

Ele não fuma dentro de casa. Ele fica ali fora, na garagem, fica num corredorzinho que tem, fica ali. Ou vai para a cozinha 
ou para o banheiro. Às vezes, quando a gente não está em casa, ele fuma na área.

Parte considerável das crianças (categoria $\mathrm{A}$ - 43,9\%) declara que os pais fumam em sua presença e se revela muito incomodada com isso. Além de sentir o mal estar do cheiro e da fumaça ...Eu não fico perto deles, fico longe, porque eu não gosto da fumaça e começo a tossir... têm consciência de serem fumantes passivas ...Mãe, pára de fumar perto de mim, porque você está fazendo eu também fumar junto com você... e têm medo de se viciarem sem querer ... A fumaça vai entrar em mim, pode me dar (vontade de) querer também fumar...

Já na categoria D (24,39\%), as crianças afirmam que os pais não fumam em sua presença, porém citam os locais onde os mesmos fumam, o que parece indicar a preocupação, tanto dos pais em poupar as crianças ... Ela (a mãe) só fuma no quarto dela, que é privacidade dela... quantos destas ao saber quando e onde os pais fumam ... Ele não fuma dentro de casa. Ele fica ali fora, na garagem, fica num corredorzinho que tem, fica ali. Ou vai para a cozinha ou para o banheiro...

\section{2 - Perfil dos pais fumantes} entrevistados

Foram entrevistados 22 pais, sendo $18(81,81 \%)$ da escola pública e 04 (18,19\%) da escola particular. Destes18 $(81,8 \%)$ eram mães e 04 pais (18,8\%), com idade variando entre 36 a 58 anos (média de 42 anos). No que concerne ao nível de escolaridade temos: 27,3\% (06 pais) com primeiro grau completo; $18,2 \%$ (04) com primeiro grau incompleto; 36,4\% (08) segun- do grau completo; 13,6\% (03) terceiro grau completo e 4,5\% (01) terceiro grau incompleto.

\section{Adultos $^{+\#}$}

\section{Questão 1}

O senhor (a) costuma fumarno lugar onde seu filho está?

Quadro III- Síntese das idéias centrais das respostas dos pais à questão 1

\begin{tabular}{|lcc|}
\hline \multicolumn{1}{|c}{ IDÉIA CENTRAL } & $\mathrm{N}^{\circ}$ & $\%$ \\
$\begin{array}{l}\text { A- Sim, fuma no local onde a } \\
\text { criança está. }\end{array}$ & 5 & 22,7 \\
$\begin{array}{l}\text { B- Não, não fuma em casa, prefere } \\
\text { fumar na rua ou no quintal. }\end{array}$ & 5 & 22,7 \\
$\begin{array}{l}\text { C- Não, fuma em casa mas } \\
\text { somente em locais determinados. }\end{array}$ & 3 & 13,7 \\
$\begin{array}{l}\text { D- Não, fuma em casa (mesmo } \\
\text { nos ambientes sociais) mas não na } \\
\text { presença da criança. }\end{array}$ & 4 & 18,2 \\
$\begin{array}{l}\text { E- Às vezes, quando não consegue } \\
\text { evitar. } \\
\text { TOTAL }\end{array}$ & 5 & 22,7 \\
\hline
\end{tabular}

\section{Gráfico III}

O SRIA COSTUMA FUMAR NO LUGAR ONDE SEU FILHO ESTÁ?

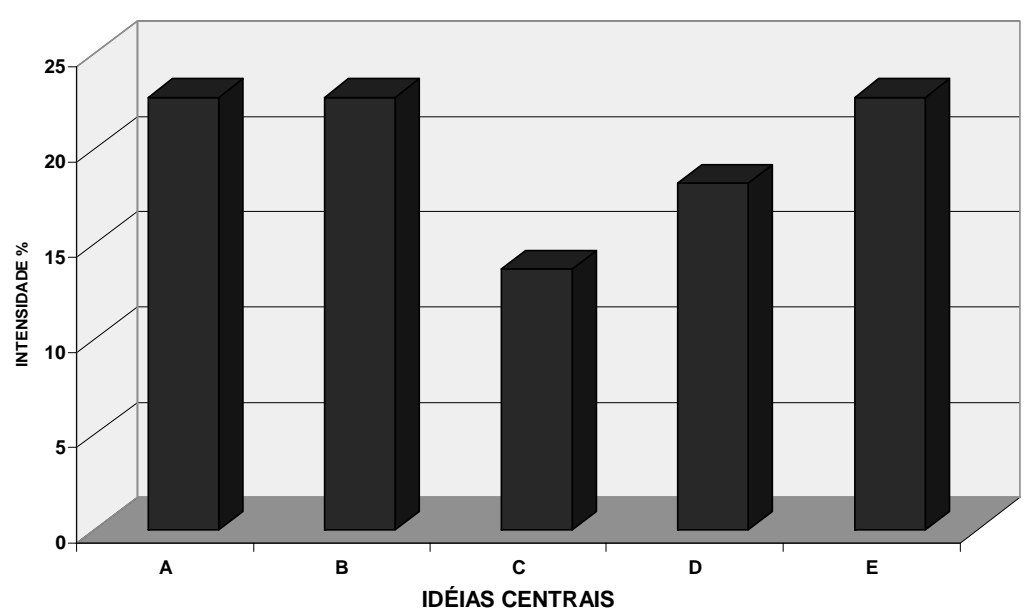

DSC A- Sim, fuma no lugar onde a criança está.

Eu sou uma pessoa que fuma, não vou

\footnotetext{
+\# Nesse artigo serão apresentados apenas os resultados referentes às questões 1 e 3.
} 
esconder. Eu já tinha parado, parei doze... quinze anos, e faz cinco que voltei, por uma questão aí bem forte. Fumo em casa e, normalmente, onde eu estou, ele está atrás de mim. Procuro fumar só da cozinha para a área de serviço mas, se ele se encontra nesse ambiente, aí eu fumo perto dele. Se eu estou no quarto dele, não fumo mas, no que diz aos ambientes sociais eu fumo normalmente. Ele reclama um pouco da fumaça. Ah, às vezes me sinto mal, entendeu?É ruim porque eu sei que está fazendo mal para ele, e mesmo assim estou cometendo o erro. Não me sinto bem fumando na frente dele. Fumo e estou sempre alertando ao mesmo tempo:"-Você nunca me pegue um cigarro, hem? Que isso aqui está me matando dia a dia, aos poucos”, que eu faço esse comentário sim, sempre. Eu sei que é errado. Geralmente ele é que sai de perto de mim, tem um ódio mortal de cigarro, é quem mais se incomoda. Isso é muito ruim, porque fica abanando com a mãozinha: “Ai, mãe, esse cheiro, ai, incomoda, mãe. Quando é que você vai parar? Você prometeu!", Ah, ele reclama muito. Realmente ele não gosta de cigarro. As meninas, elas fala que faz mal, que o sonho delas é que eu não fumasse. No Natal pedem de presente eu parar de fumar, essas coisas. E eu sei que eu estou devendo isso: parar. Mas eu vou ver se até o final do ano eu dou esse presentinho para eles. [RINDO]

DSC B- Não, não fuma em casa, prefere fumar na rua ou no quintal.

Não, eu fumo fora de casa. Eu vou para a sacada, fecho a porta e lá eu fumo, mesmo porque eu não gosto do cheiro do cigarro dentro da minha casa, eu não suporto.Ou eu fumo no quintal; geralmente, se ele está lá brincando, eu espero ele entrar, aí vou lá. Tenho meu cantinho, meu cinzeirinho, e fumo um cigarrinho. Em ambientes fechados também não fumo. Se eu chego em casa e alguém fumou na minha sala, eu fico muito brava. Eu não gosto, nunca gostei, mesmo porque eu não posso deixar - né? Eu estou me prejudicando, não vou prejudicar meus filhos, mesmo porque eu sei que eu não estou dando um bom exemplo para eles fumando. Meu marido não fuma, não suporta o cheiro de cigarro, a minha sogra também não. Então fumo no quintal quando estou em casa, quando não estou, fumo na rua. Fumo mais na rua. Quando eu termino o meu trabalho, que eu saio para a rua, para vir prá casa, eu acendo o meu cigarrinho e fumo na rua.

DSC E- Às vezes, quando não consegue evitar.

Às vezes sim, mas normalmente não. Como ninguém tem vício lá em casa, só eu mesmo, então às vezes eu tenho que fumar lá fora. Quer dizer, evito ao máximo, né? Às vezes eu tenho vontade de fumar junto com eles, mas prejudica eles também, né? Então evito, não tenho o hábito, mas às vezes eu fumo, mas eles não gostam não. Se ele tá num lugar e eu estou fazendo alguma coisa, eu fumo. É ruim, para mim. Eu me sinto mal, porque sei do mal que estou fazendo, mas eu não consigo parar com o cigarro. É uma sensação muito desagradável, porque eles detestam. Só o cheiro já... “Ai, mãe, pára com isso!" É muito difícil. Eu procuro fumar lá fora, na lavanderia. Procuro não fumar dentro de casa, porque sei que atrapalha quem não fuma, né? ? Então fumo fora, numa arinha que eu tenho. Meu cigarro fica lá, meu cinzeiro fica fora. Às vezes no banheiro [RINDO], que é o lugar mais ideal, porque fica sentado lá, né? Então eu procuro ficar longe de quem não fuma, mas de vez em quando não dá. Ocorrem algumas situações em que você está em algum local público e que, passado um certo período, você tem necessidade de fumar. Então eu acabo até fumando. Mas 
dentro de casa, por exemplo, não fumo; dentro do carro não fumo; evito ao máximo. Geralmente eu fumo na lavanderia lá do meu apartamento. Fumar na frente não. Se está muito frio, eu vou fumar na cozinha...às vezes eles estão na sala. Mas, assim, cara a cara, não.

É relativamente pequeno (22\%) o número de discursos de pais que declaram fumar na presença dos filhos, o que parece denotar uma sensibilização deles pelas campanhas anti-fumo e pelo próprio apelo dos filhos. Percebe-se, na maioria, uma preocupação em poupar os filhos da fumaça e uma consciência dos males para o fumante passivo ...É ruim porque eu sei que está fazendo mal para ele, e mesmo assim estou cometendo o erro.. A maioria tem consciência que os filhos não suportam cheiro ...Ai, mãe, esse cheiro, ai, incomoda, mãe. Quando é que você vai parar? Você prometeu! e não gostam que os pais fumem. ...Geralmente ele é que sai de perto de mim, tem um ódio mortal de cigarro, é quem mais se incomoda... Mas também reconhecem a força do vício e parecem saber que estão prejudicando os filhos. Grande parte dos discursos versa sobre o esforço em fumar em locais específicos, visando poupar os filhos ...Eu vou para a sacada, fecho a porta e lá eu fumo... mas, ao mesmo tempo, alguns reconhecem a limitação desse ato ... Eu procuro fumar lá fora, na lavanderia. Procuro não fumar dentro de casa, porque sei que atrapalha quem não fuma, né? Então fumo fora, numa arinha que eu tenho. Meu cigarro fica lá, meu cinzeiro fica fora...Por último, existem algumas declarações "radicais” de pais que afirmam fumar, exclusivamente, fora de casa ... Não, eu fumo fora de casa... Eu estou me prejudicando, não vou prejudicar meus filhos.
Questão3

Você acha que seu filho vai fumar?

Quadro IV

\begin{tabular}{|l|c|c|}
\hline \multicolumn{1}{|c|}{ IDÉIA CENTRAL } & $\mathrm{N}^{\circ}$ & $\%$ \\
\hline A-Acha que não & 11 & 50,0 \\
\hline B-Espera que não & 4 & 18,1 \\
\hline C-Acha que sim & 2 & 9,0 \\
\hline D-Não sabe & 5 & 22,9 \\
\hline TOTAL & 22 & 100 \\
\hline
\end{tabular}

Gráfico IV

VOCÊ ACHA QUE SEU FILHO VAI FUMAR?

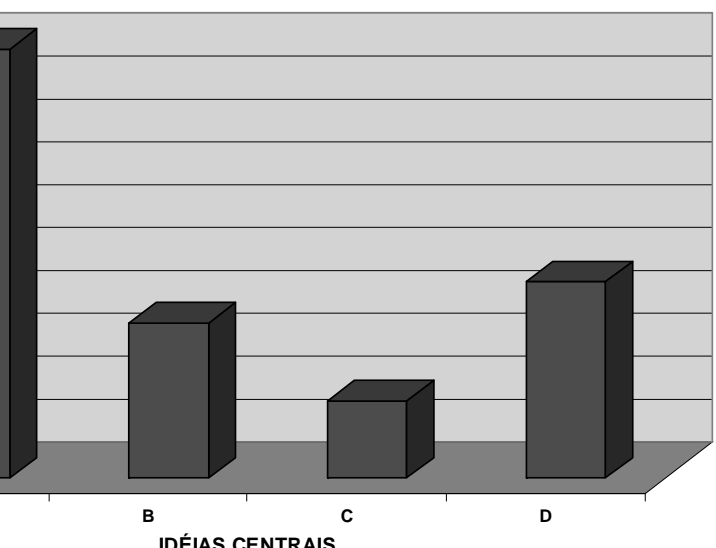

Idéia Central A -Acha que não

DSC A- Acha que não

Não, eu acho que não porque eu ensino ele, falo: "Nunca faça isso.” Dou muita orientação, converso muito : "Não faz isso. Não fuma." É um vício que é difícil tirar. Acho que ele tem uma opinião bem formada sobre cigarro, que não faz bem, que não é legal. Acho que não também porque ele não gosta. Ele não gosta nem do cheiro de cigarro, ele odeia o cigarro, detesta. Ainda bem... Ele tem pavor do cigarro, e a vida dele é lutar para eu parar de fumar. Acho que isso é uma coisa desde pequenininho dele. Talvez vendo na escolinha porque sempre fazem campanhas. Hoje em dia tem no maço de cigarro. Quando ele pega o meu maço de ci- 
garro, tem lá aquela fotografia da mulher toda entubada. "Vê, mãe? Isso faz mal, mãe! Isso não é bom". Ele critica bastante, critica mesmo. Tem bronca quando vê eu acender um cigarro. Quando eu estou lá fora às vezes ele vai lá. Falo: "Vai para lá, deixa a mãe. A mãe está fumando, depois a gente conversa." Às vezes ele não vai. "Pára de fumar! não vê que o cigarro faz mal? Passa todo dia na televisão que o cigarro faz mal." Está sempre criticando. Já jogou vários maços de cigarro meus na água... [RINDO] Não brigo com ele. Eu vou lá e compro outro e pronto. [RINDO] Não brigo, porque eu estou errada.. Ele se preocupa com a saúde, com a minha saúde, fala: "Morre tanta gente de câncer, de doença de cigarro, e eu não quero que a minha mãe morre!" [RINDO] Tadinho! É duro, não é? Eu acabo às vezes nem fumando muito, entendeu? Se eu for fumar, vai ser um só. Estou tirando de pouco a pouco, estou fumando bem pouco - um, dois por dia, no máximo. Mas eu vou deixar. Não é legal, mesmo porque o cheiro incomoda as pessoas, não é. Eu sei que o cheiro é insuportável. Eu fumo, mas eu não gosto do cheiro. Se meu filho falar: "Mãe, eu não quero que a senhora vai fumar mais no banheiro", ou "aí fora não quero ver a senhora fumando" evito para eles não vê. Mas o menino e o meu marido brigam comigo: "Por que é que não deixa desse cigarro?” Tem a hora que eu paro, assim, para pensar: "Meu Deus do céu, será que eu vou conseguir deixar?" Porque largar de tudo, é difícil. Às vezes eu fico umas horas sem fumar, mas vem aquele desespero. Daí eu fumo um atrás do outro... É. É difícil

rDSC B- Espera que não.

Eu espero que não. Quando eu estou fumando, ele briga. "Mãe, já está fumando de novo?"... Que eu fumo na hora que ele está dormindo, E eu fumo no banheiro. Mas tem... é... tem vez que ele ainda está acorda- do. Meu marido fuma no lugar em que ele está. Ele fica reclamando. "Ah, esse cheiro de cigarro, ah, dá câncer, né?”... Um monte de coisa. Meu filho faz campanha para que eu pare de fumar. É bem consciente do que é ruim no fumo. Não aprecia. Então eu espero que não. Espero que não mesmo, porque faz mal. Falo com ele. Porque eu acho que eu sou do tempo em que fumar era bonito. A mídia fumava, os outdoors eram de cigarro, no cinema tinha muito cigarro. Hoje você vê uma campanha contrária ao fumo. Em ambientes em que eu trabalho eu sou uma das únicas fumantes. Eu acho que é um bom dado. Os fumantes estão ficando meio raridade, e eu espero que seja assim mesmo. Que nem eu já falei para ele: "Eu sou uma viciada em cigarro." Então ele não quer (fumar), ele já tem instinto de não gostar, entendeu? E ele me falou que não gosta.A gente fala para não fumar, mas eu não vou ter autonomia para falar: "Para de cigarro, não vai fumar." Porque eu fumo, não é? É uma das coisas que eu vou ter problemas : para of futuro se ele querer fumar, vai ser complicado para mim; a não ser que eu pare realmente de fumar, que aí vou ter mais punho para falar com ele, autoridade: "Eu não fumo, por que vai fumar?" Mas eu sou uma fumante! Então vai ficar meio complicado para mim, não é?

\section{DSC D- Não sabe}

Eu não posso afirmar se ela vai fumar ou não. Eu acredito que não. Ela tem mais consciência do que eu a respeito do cigarro. Mas não sei. Pai e mãe fumam! Ela fala que não, fala: "Mãe, pára. Você vai morrer. Eu não vou fumar quando eu crescer." Se continuar reagindo da forma que está, não é? Até agora, pelo menos, a vontade dela é de não fumar...Então não vou falar "Não, não vai fumar." Aí é a cabeça dela. Ela tem um exemplo dentro de casa e ela gosta de me imitar. Eu acho que, com o tem- 
po... Não tenho certeza, mas acho que em algum determinado momento ela possa vir a fumar, mais por imitar. Então não sei, depende mais dela do que de mim. Ainda ontem eu estava debatendo esse assunto com um amigo que falou: "A minha filha sempre abominou o cigarro. Quando foi um determinado dia, eu peguei ela fumando. Eu nunca podia esperar que a minha filha fosse fumar ! "E eu acho que, no caso dos meus filhos, eu e meu marido, somos uma influência ruim . Meu marido mais que eu! [RINDO] Mas é uma bagunça! Porque ele fuma mais que eu, mas eu estou fumando da mesma forma, não é?

A maioria dos discursos dos pais sobre a idéia de seus filhos virem a fumar indica que eles não acreditam em tal possibilidade (50\%). ...Não, eu acho que não porque eu ensino ele, falo: “Nunca faça isso."... Dou muita orientação, converso muito: "Não faz isso. Não fuma."... É um vício que é difícil tirar... Acho que ele tem uma opinião bem formada sobre cigarro, que não faz bem, que não é legal... Acho que não também porque ele não gosta...Cerca de 18,1\% dos entrevistados espera que os filhos não fumem ...Meu filho faz campanha para que eu pare de fumar. É bem consciente do que é ruim no fumo. Não aprecia. Então eu espero que não. Espero que não mesmo... É interessante observar esta opinião em contraste com a de seus próprios filhos que declaram que as crianças que fumam, o fazem por imitação dos pais. Existe, no entanto uma pequena porcentagem de entrevistados que embora não gostando, reconhecem a sua influência sobre a possibilidade concreta do filho vir a fumar.

\section{CONSIDERAÇÕES FINAIS}

Os discursos coletivos gerados nesta pesquisa fornecem importantes eixos explicati- vos sobre o tema da dinâmica familiar resultante da situação do fumo passivo, fulcro do presente artigo.

Como não seria possível no espaço deste artigo explorar todos eles, discutiremos alguns que consideramos relevantes.

\section{A fumaça como face visível da "doença cigarro"}

Emerge dos discursos que o cheiro do cigarro, ou da fumaça do cigarro é percebido mormente pelo não fumante, como é caso do fumante passivo, como um elemento irritante, quando presente num ambiente confinado como o doméstico; a fumaça agride o próximo, sendo, nesse sentido, uma desconsideração do outro, que pode gerar um clima de conflito no ambiente doméstico, como ilustra esta fala do sujeito coletivo: O meu pai fuma perto de mim, eu falo" apaga isso aí, eu não gosto" Ai ele fala: "então sai daqui".

Este diálogo (que tem como representação social pressuposta a clássica expressão: “os incomodados se retirem”) é revelador de um tipo de relação pais/filhos onde o poder paterno é forte a ponto de prevalecer mesmo quando associado a um comportamento claramente inadequado como o de poluir o ambiente pela fumaça do cigarro: quem pratica o a ato inadequado é o pai, mas como este é “puro poder”, quem é punido ("então saia daqui") é o filho. Há ai claramente um problema no exercício da paternagem ${ }^{14}$ com prejuízo para o desenvolvimento da criança na medida em que aquele que deveria ser o Portador da Verdade (o Pai) aparece para o filho como o Portador do Erro.

Por outro lado, a fumaça é a face visível, ou, em termos semióticos a dimensão significante, concretamente vivenciada, do cigarro e de seus efeitos maléficos, que contrasta com os teóricos e distantes efeitos adversos (probabilidade de ter câncer na velhice, etc.). 
A fumaça é poluição próxima, por isso doença visível, sensível pelo olfato, irritante para os olhos, o que implica ato explicitamente delituoso, a ser, portanto, praticado clandestinamente ou fora do convívio social. Ora isso traduz, em termos psicanalíticos, uma evidente fantasia, com todas as conseqüências associadas: para que não haja, no plano da fantasia, uma doença e seus efeitos - a doença provocada pela fumaça do cigarro- instala-se, no plano do real, outra doença, a doença da clandestinidade, da marginalidade, da exclusão, do ocultamento, o que, de fato, consubstancia a fantasia da eliminação do evento pelo ocultamento da sua face visível (fenômeno que tem como representação social a também clássica expressão: “o que os olhos não vêm o coração não sente”).

\section{O cigarro, terror e reducionismo didático}

O terror, qualquer que seja (o político, o doméstico, o pedagógico) é, sempre, uma esquematização, uma caricatura, uma simplificação, que remete ao homem unidimensional de que fala Marcuse ${ }^{15} \mathrm{e}$, conseqüentemente às idéias do Mal Absoluto, com os conseqüentes desdobramentos comportamentais e de políticas públicas fundadas em propostas do tipo “tolerância zero".

Os DSCs aqui presentes remetem a fantasias de morte, destruição, degradação, inclusive moral, ligadas ao ato de fumar, que repercutem discursos amplamente difundidos por todo o tecido social e que implicam simplificação extrema da realidade. Tal simplificação impede que se veja que o cigarro (e também o álcool, as outras drogas) é, também, paz, alívio da tensão, companheirismo (um belo exemplo disso é o papel do cigarro na obra de Graciliano Ramos), charme, até “ombro amigo”, ou seja, um ente polissêmico.

Tal simplificação fica claramente manifesta na dificuldade que se apresenta hoje para o educador e para o comunicador de superar a postura conservadora segundo a qual explicar o Mal implicaria justificar ou aceitar o Mal.

Ora, explicar - ato pedagógico básico e necessário - qualquer coisa, inclusive o Mal, é um ato em si, que se auto justifica e que não pode estar preso a qualquer julgamento de valor; assim, explicar é apenas e tão somente buscar entender. Assim, quando se busca entender,inevitavelmente se cai na complexidade, na ambigüidade, na ambivalência, que muito freqüentemente, desencadeia a reação conservadora de medo. Tal medo, por sua vez, dá lugar, no ambiente escolar, ao terror pedagógico e comunicacional da tolerância zero que, entre outras coisas, impede, como este extrato de DSC revela - Não sei nem porque o cigarro veio a existir, porque o cigarro só faz mal - que o escolar entenda porque as pessoas fumam, e que fumar não é uma manifestação de irracionalidade.

A Escola não pode sucumbir à tentação de usar o terrorismo pedagógico como método em nada, o que inclui também o tabagismo; ela precisa sim trabalhar a questão em todos os seus aspectos, inclusive aqueles que dizem respeito à dinâmica familiar do aluno, para que, a partir daí, o aluno possa tomar a sua decisão pessoal: fumar ou não fumar

\section{O cigarro e a inversão do poder na rela- ção pais-filhos}

...É ruim porque eu sei que está fazendo mal para ele, e mesmo assim estou cometendo o erro. Não me sinto bem fumando na frente dele. Fumo e estou sempre alertando ao mesmo tempo: "-Você nunca me pegue um cigarro, hem? Que isso aqui está me matando dia a dia, aos poucos"..... Eu sei que é errado. Geralmente ele é que sai de perto de mim, tem um ódio mortal de cigarro, é quem mais se incomoda. Isso é muito ruim, porque fica abanando com a mãozinha: "Ai, mãe, 
esse cheiro, ai, incomoda, mãe. Quando é que você vai parar? Você prometeu! ”...

Este discurso revela a situação oposta do “puro poder” onde, como assinalamos, quem pratica o a ato inadequado é o pai, mas como este é “puro poder”, quem é punido ("então saia daqui”) é o filho. Aqui o pai-portadordo-erro é também portador da culpa, das promessas não cumpridas, da educação pelo contra exemplo, necessitando, por isso ser "educado" pelos filhos.

A relação pais e filhos envolvendo a problemática do fumo passivo recoloca pois,uma velha questão da educação em saúde que usam os filhos como objeto das ações e campanhas sanitárias na suposição de que, enquanto ainda não portadores dos “vícios do adulto” os filhos podem representar fator de educação sanitária da família.

A questão que fica é se a família, lócus natural do poder das gerações mais velhas sobre os mais jovens, que constitui a própria definição tradicional da educação, suportaria tal pedagogia subversiva.

\section{Recomendações}

Ao final deste trabalho cremos ser importante assinalar que a pesquisa revela, no que toca aos sentidos associados ao tabagismo passivo, um quadro, tanto da parte dos pais quanto dos escolares, cheio de fantasias, de terror, de culpa, de desinformação, que reflete uma dificuldade nossa, da cultura brasileira atual, de enfrentar a questão, seus desdobramentos e conseqüências, de uma forma que, sem minimizar a gravidade do problema, consiga, situá-lo em termos realistas, condição sine qua non para seu devido equacionamento prático.

Acreditamos pois ser importante, entre outras coisas, advogar pela utilização pedagógica dos resultados encontrados aqui, através da apresentação dos discursos e de suas expressões quantitativas aos escolares desta faixa etária e a aos pais de escolares, nas escolas públicas e particulares do país (uma vez que se acredita que os resultados não carregam marcas maiores do fato da pesquisa ter sido feita na cidade de São Paulo).

Na utilização escolar, com os alunos, dos resultados desta pesquisa, um material rico e denso como o presente permite que o professor lance mão de toda o arsenal de técnicas pedagógicas visando obter o maior benefício pedagógico possível desta “devolutiva” termos cognitivos, atitudinais e comportamentais.

Já com relação aos pais deve-se potencializar tanto os argumentos e justificativas presentes nos discursos da própria “categoria”, para que os pais possam se perceber enquanto coletividade e possam perceber a imagem que seus filhos fazem da sua condição de fumante e dos efeitos deste hábito junto às crianças.

Finalmente vale acrescentar que outras pesquisas devem ser desenvolvidas com populações numericamente mais expressivas de pais e crianças de diferentes níveis sócio econômicos (supondo-se que, em nosso país, crianças de escolas públicas e privadas apresentem níveis sócio econômicos distintos) a fim de se verificar, o que não foi possível ser feito no presente estudo em função do pequeno porte da amostra, se os resultados aqui apresentados apresentam diferenças por extratos sócio econômicos.

Abstract: The objective of this research project was to achieve a better understanding of family
dynamics in smoking parents' homes. The focus is on the relationship between smoking parents
and their children and the central theme is the fact that passive smoking is the third biggest cause
of preventable deaths in the world. Forty-one children and 22 adults participated in the study.
The methodology involved is the Discourse of the Collective Subject (in Portuguese, DSC),
which depicts a quali-quantitative profile. The findings revealed that the children emphasized
that smoking parents could lead the children to smoke themselves; however, they do not intend 
to smoke and the most frequent reason mentioned was fear of illnesses and death. A substantial part of the kids stated that the parents smoke in their presence, which they deeply dislike and resent. But parents say they try not to do it, displaying some awareness of the hazards to the passive smoker. Because the present research is an initial study, with a small sample, the conclusions cannot be generalized to all types of pre-adolescents. However, from a qualitative point of view, the results suggest a broad variety of subjects and sub-subjects to be explored in future research studies.

Key words: Tobaccoism, Passive Smoker, Discourse of the Collective Subject.

\section{REFERÊNCIAS}

1. Rosemberg J. Tabagismo: sério problema de saúde pública. São Paulo: Edusp; 1981.

2. Mahler H. Tabaco o salud: elija la salud. Foro Mund Salud. 1988;9:80-5.

3. Ferreira S, Souza RB, Sant'Anna CC. Saúde pulmonar e tabagismo passivo em amostra de escolares na cidade do Rio de Janeiro: estudo piloto. Arq Bras Med. 1993;67(3):202-7.

4. Kumar M, Melville GN. Effects of parental smoking on ventilatory function in children. Am Rev Respir Dis. 1983;127(2):187.

5. Rosemberg J. Nocividade à saúde das crianças, conseqüente do tabagismo dos pais. AMB Rev Assoc Med Bras. 1985;31(1-2):2-6.

6. Kurz H, Frischer T, Huber WD, Gotz M. Adverse health effects in children caused by passive smoking. Wien Med Wochenschr. 1994;144(22-23):531-4.

7. Candeias NMF, Marcondes RS. Diagnóstico em educação em saúde: um modelo para ensinar as relações entre atitudes e práticas na área da saúde pública. Rev Saúde Pública. 1979;13(2):63-8.

8. Green LW, Kreuter MW. Health promotion planning: an educational and environmental approach. Mountain View (CA): Mayfield Publishing; 1991.

9. Bott M, Cobb AK, Scheibmeir MS, O’Connell KA. Quitting: smokers relate their experiences. Qual Health Res. 1997;7(2):255-69.

10. Minayo MCS. O desafio do conhecimento: pesquisa qualitativa em saúde. São Paulo: Hucitec/Abrasco; 1992.

11. Minayo MCS, organizador. Pesquisa social: teoria, método e criatividade. Petrópolis: Vozes; 1994.

12. Simioni AMC, Lefèvre F, Bicudo Pereira IMT. Metodologia qualitativa e as pesquisas em saúde coletiva: considerações teóricas e instrumentais. São Paulo: Universidade de São. Paulo, Faculdade de Saúde Pública, Departamento de Prática de Saúde Pública; 1996.

13. Lefèvre F, Lefèvre AMC. O discurso do sujeito coletivo: um novo enfoque em pesquisa qualitativa (desdobramentos). Caxias do Sul: Educs; 2003.

14. Rezende ALM, Alonso ILK. O perfil do pai cuidador. Rev Bras Crescimento Desenvolv Hum. 1995;5(1-2):66-81.

15. Marcuse H. A ideologia da sociedade industrial: o homem unidemensional. Rio de Janeiro: Zahar; 1977. 